\title{
PENGARUH KOMPETENSI PEGAWAITERHADAP PENERAPAN ELECTRONIC GOVERNMNENT DI DESA TIMORENG PANUA KECAMATAN PANCA RIJANG KABUPATEN SIDENRENG RAPPANG
}

\author{
${ }^{1)}$ Feby Anggunita, ${ }^{2}$ Sofyan, ${ }^{3)}$ Andi Ilham \\ Fakultas IImu Sosial dan IImu Politik Universitas Muhammadiyah Sidenreng Rappang \\ febyanggunita02@gmail.com
}

\begin{abstract}
Abstrak
Pengaruh kompetensi pegawai di Desa Timoreng Panua Kecamatan Panca Rijang Kabupaten Sidenreng Rappang, 2) untuk mengetahui penerapan electronic government di Desa Timoreng Panua Kecamatan Panca Rijang Kabupaten Sidenreng Rappang, dan 3) untuk mengetahui pengaruh kompetensi pegawai terhadap penerapan electronic government di Desa Timoreng Panua Kecamatan Panca Rijang Kabupaten Sidenreng Rappang. Populasi dalam penelitian ini mencakup seluruh Kepala Keluarga yang terdiri dari 2 ( dua ) dusun berjumlah 547 Kepala Keluarga. Teknik pengambilan sampel adalah probability sampling, jumlah sampel dalam penelitian ini sebesar 85 Kepala Keluarga. Teknik pengumpulan data menggunakan observasi, kuesione, dokumentasi, dan wawancara. Teknik analisis data kuantitatif yang digunakan yaitu analisis distribusi frekuensi dan analisis regresi linear sederhana. Hasil penelitian menunjukkan bahwa: 1) kompetensi pegawai termasuk kategori cukup baik dengan rata-rata persentase sebesar 58,3\%,2) electronic government termasuk kategori cukup baik dengan rata-rata persentase sebesar 56,9\%,3) kompetensi pegawai berpengaruh terhadap penerapan electronic government, hal ini dibuktikan melalui output data dari tabel summary $R^{2}$ sebesar 0,603 atau $60,3 \%$. Nilai $t$ hitung $=6,881>t$ tabel 1,992 dengan nilai signifikansi $0,000<0,05$. Sehingga ada pengaruh yang nyata ( signifikan ) varibel kompetensi pegawai $(\mathrm{X})$ terhadap variabel electronic government $(\mathrm{Y})$ di Desa Timoreng Panua Kecamatan Panca Rijang Kabupaten Sidenreng Rappang.
\end{abstract}

Kata Kunci: Kompetensi Pegawai dan Electronic Government

\begin{abstract}
The effect of employee competence in Timoreng Panua Village, Panca Rijang District, Sidenreng Rappang Regency,2) to determine the application of electronic government in Timoreng Panua Village, Panca Rijang District, Sidenreng Rappang Regency, and 3) to determine the effect of employee competence on electronic application government in Timoreng Panua Village, Panca Rijang District, Sidenreng Rappang Regency. The population in this study included all family heads consisting of 2 (two) hamlets totaling 574 families. The sampling technique is probability sampling, the member of samples in this study amounted to 85 households. Data collecton technique using of observation, questionnaires, documentation, and interviews. Quantitative data analysis techniques used are frequency distribution analysis and simple linear regression analysis. The result showed that: 1) employee competencies were quite good with an average percentage of 58,3\%, 2) electronic government was quite good with an average percentage of $56,9 \%$, 3) employee competence affected the implementation electronic government, this is proven through data output from summary table $R^{2}$ of 0,603 or $60,3 \%$. $T$ value $=6,881>1,992$ table with significance value of $0,000<0,05$. So there is a significant (significant) influence of employee competency variable $(X)$ on electronic government variables (Y) in Timoreng Panua Village, Panca Rijang District, Sidenreng Rappang Regency.
\end{abstract}

Keywords : Employee Competence and Electronic Government

PRAJA $\mid$ Volume 8| Nomor 3| Edisi Oktober 2020 


\section{A. PENDAHULUAN}

Berkembangnya teknologi informasi dan komunikasi yang sangat drastis ini dengan menggunakan hardware (perangkat keras) dan software (perangkat lunak) dengan kapasitas yang sangat tinggi. Teknologi informasi dan komunikasi sudah di desain secara baik dengan dilengkapi beberapa fitur-fitur terbaik dan dapat digunakan dalam berbagai bidang melalui dari bidang usaha, perkantoran, pendidikan, kesehatan maupun pemerintahan. Aplikasi teknologi informasi dan komunikasi seperti internet adalah alat yang dapat dipakai untuk meningkatkan akses public terhadap proses penyelenggaraan negara, meningkatkan interaksi dengan para pejabat dan pemimpin pemerintahan, serta memungkinkan rakyat mengurus berbagai macam pelayanan pemerintah seperti mengurus perizinan, membayar pajak, mengakses perpustakaan, membuat KTP, atau mengikuti pendidikan, secara online. (Setiyono, 2012).

Kemajuan teknologi informasi memberikan manfaat yang sangat besar bagi para pekerja yang bergelut dengan dunia electronic khususnya dalam pemerintahan, karena electronic tersebut tidak hanya digunakan dalam media pembelajaran maupun perkantoran, tetapi yang namanya electronic juga digunakan dalam pemerintahan yang dinamakan Electronic Government atau yang sering disingkat $E$ Gov. Pemerintah saat ini dihadapkan pada tantangan kebutuhan masyarakat yang menuntut adanya pelayanan efektif dan efisien melalui teknologi informasi dan komunikasi.

Tujuan awal adanya e-government adalah bagaimana pemerintah menggunakan teknologi informasi secara inovatif yang dapat memudahkan masyarakat mendapat informasi dan meningkatkan kualitas pelayanan. (Ramdani, 2018). Berdasarkan Peraturan Presiden Republik Indonesia Nomor 95 Tahun 2018 tentang Sistem Pemerintahan Berbasis Elektronik Pasal 1 ayat 3 Manajemen SPBE adalah serangkaian proses untuk mencapai penerapan SPBE yang efektif, efisien, dan berkesinambungan, serta layanan SPBE yang berkualitas. Untuk memaksimalkan penerapan Sistem Pemerintahan Berbasis Elektronik atau electronic government maka diperlukan adanya kompetensi pada setiap pegawai yang bekerja dibagian ini.

Seorang pegawai merupakan penggerak organisasi, maka setiap pegawai harus memiliki kinerja yang selalu meningkat, dengan adanya peningkatan kinerja maka pegawai akan diarahkan agar memiliki sikap yang loyalitas, bertanggungjawab, dan berkompeten. Kompetensi sangat dibutuhkan untuk memaksimalkan penerapan electronic government agar pegawai dapat menjalankan atau memahami bagaimana cara menggunakan dan mengoperasionalkan electronic government, Untuk memaksimalkan penerapan electronic government maka diperlukan adanya kompetensi, Tandelilin mengatakan Kompetensi memiliki empat variabel yaitu (1) pengetahuan (knowledge), (2) keahlian (skill), (3) kemampuan (ability) dan (4) sikap (attitude). (Asnan Mardianto, Wahjoe Pangestoeti, 2015). Berdasarkan dengan apa yang telah dijelaskan diatas, maka adapun judul yang diangkat yaitu "Pengaruh Kompetensi Pegawai terhadap Penerapan Electronic Government di Desa Timoreng Panua Kecamatan Panca Rijang Kabupaten Sidenreng Rappang dengan tujuan untuk mengetahui Pengaruh Kompetensi pegawai di Desa Timoreng Panua, untuk mengetahui Penerapan Electronic Government di Desa Timoreng Panua, dan untuk mengetahui Pengaruh Kompetensi Pegawai terhadap Penerapan Electronic Government di Desa Timoreng Panua.

Dharma (Suhartini, 2014) mengatakan Kompetensi adalah suatu kemampuan untuk melaksanakan atau melakukan suatu pekerjaan atau tugas yang dilandasi atas keterampilan dan pengetahuan serta didukung oleh sikap kerja. Tandelilin (Asnan Mardianto, Wahjoe Pangestoeti, 2015) mengatakan Kompetensi memiliki empat variabel atau indikator yaitu sebagai berikut:

1. Pengetahuan (knowledge). Suriasumantri (Sakti, 2011) mengatakan Pengetahuan adalah segenap apa yang diketahui manusia tentang suatu objek tertentu yang merupakan ilmu yang secara langsung atau tidak langsung. Berdasarkan pengertian pengetahuan di atas maka 
disimpulkan adalah pengetahuan merupakan sesuatu yang diketahui oleh manusia tentang suatu hal baik secara langsung maupun tidak langsung.

2. Keahlian (skill). Harrison dan Rainer (Rahmi, 2013) Keahlian adalah suatu perkiraan atas suatu kemampuan seseorang untuk melaksanakan pekerjaan dengan sukses. Keahlian dibutuhkan oleh seorang pekerja atau pegawai karena tanpa adanya keahlian maka pegawai tersebut tidak bisa dikatakan kompeten.

3. Kemampuan (ability). Asnan Mardianto, Wahjoe Pangestoeti, 2015 Kemampuan adalah kesanggupan yang dimiliki oleh seseorang yang dapat dilihat dari cara bersikap, cara berpikir, dan cara bertindak dalam melakukan suatu pekerjaan. Kemampuan merupakan sesuatu yang ada pada diri seseorang sehingga dapat melakukan sebuah pekerjaan yang didasari ilmu.

4. Sikap (attitude). Spencer dan Spencer (Handayan, n.d.) mengatakan sikap dan nilai-nilai yang dimiliki seseorang percaya diri merupakan keyakinan orang bahwa mereka dapat efektif dalam hamper setiap situasi. Sikap yaitu sesuatu atau karakteristik yang melekat pada diri seseorang yang membedakannya antara manusia yang lain.

R. Eko Indrajit (Azkiya, 2018) mengatakan bahwa e-government merupakan suatu mekanisme interaksi baru antar pemerintah dengan masyarakat dan kalangan lain yang berkepentingan, dengan melibatkan penggunaan teknologi informasi dengan tujuan meningkatkan pelayanan dengan meningkatkan efisiensi, efektivitas, transparansi, dan akuntabilitas. (Hayati dan Eko Priyo Purnomo, 2017) Adapun indikator dalam penyelenggaraan e-government ada empat yaitu :

1. Efisiensi. Zainuddin, 2017 Efisiensi menunjukkan kemampuan organisasi dalam menggunakan sumber daya dengan benar dan tidak pemborosan.

2. Efektivitas. Mardiasmo (Julita, 2014) menyatakan bahwa Efektivitas yaitu suatu keadaan tercapainya tujuan yang diharapkan atau dikehendaki.

3. Transparansi. Mardiasmo (Zainuddin, 2017) mengatakan bahwa Transparansi adalah keterbukaan pemerintah dalam memberikan informasi yang terkait dengan aktivitas pengelolaan sumberdaya public yang membutuhkan yaitu masyarakat.

4. Akuntabilitas. Triadji (Irvan Permana, 2011) mengatakan Akuntabilitas adalah pertanggung jawaban atas segala sesuatu tindakan seseorang (pimpinan/lembaga) yang memberi wewenang .

\section{B. METODE PENELITIAN}

Penerapan electronic government sebagai variabel dependen (terikat). Penelitian yang digunakan adalah deskriptif kuantitatif yaitu metode yang lebih menekankan pada aspek pengukuran secara obyektif terhadap fenomena sosial. Populasi dalam penelitian ini sebanyak 574 Kepala Keluarga yang terdiri dari dua dusun di Desa Timoreng Panua. Jumlah sampel adalah sebanyak 85 Kepala Keluarga. Teknik penarikan sampel yang digunakan probability sampling. Teknik pengumpulan data yang digunakan yaitu: observasi, kuesioner, dokumentasi, dan wawancara. Hasil analisis berupa analisis distribusi frekuensi, uji kualitas data, model regresi dan pengujian hipotesa.

\section{HASIL DAN PEMBAHASAN}

1. Hasil penelitian Kompetensi Pegawai (X)
a. Pengetahuan dengan rata-rata persentase sebesar $60,6 \%$
b. Keahlian dengan rata-rata persentase sebesar $56,2 \%$
c. Kemampuan dengan rata-rata persentase sebesar $58 \%$
d. Sikap dengan rata-rata persentase sebesar $58,4 \%$
Dari rekapitulasi rata-rata persentase ke empat indikator kompetensi pegawai di Desa Timoreng Panua diperoleh hasil yakni $58,3 \%$ dengan kategori cukup baik.

2. Hasil penelitian Electronic Government (Y)

a. Efisiensi dengan rata-rata persentase sebesar $58,8 \%$

b. Efektivitas dengan rata-rata persentase sebesar $60,2 \%$

c. Transparansi dengan rata-rata persentase $52,2 \%$

d. Akuntabilitas dengan rata-rata persentase sebesar $56,6 \%$

Dari rekapitulasi rata-rata persentase ke empat indikator electronic government di Desa Timoreng Panua diperoleh hasil yakni $56,9 \%$ dengan kategori cukup baik.

\section{Uji Validitas}

PRAJA | Volume 8| Nomor 3| Edisi Oktober 2020 
Kompetensi pegawai (X) dinyatakan valid dengan nilai corrected item-total correlation lebih besar dari $>0,25-0,30$ (corrected item- total correlation $>0,25-0,30$ ) yaitu, X1:0,279, X2:0,608, X3:0,479, $X 4: 0,330$.

Electronic government $(\mathrm{Y})$ dinyatakan valid dengan nilai corrected item-total correlation lebih besar dari $>0,25-0,30$ (corrected item-total correlation $>0,25-0,30$ ) yaitu, $\quad \mathrm{Y1}: 0,669, \quad \mathrm{Y} 2: 0,479, \mathrm{Y3}: 0,597$, Y4:0,623.

\section{Uji Reliabilitas}

Berdasarkan tabel reliability statistic di atas, kuesioner penelitian yang digunakan untuk mengukur variabel kompetens pegawai (X) dikatakan reliabel karena Cronbach Alpha yang diperoleh adalah sebesar 0,630 yang berarti lebih besar dari 0,60 $(0,630>0,60)$.

Berdasarkan tabel reliability statisticdi atas, kuesioner penelitian yang digunakan untuk mengukur variabel electronic government $(Y)$ dikatakan reliabel karena Cronbach Alpha yang diperoleh adalah sebesar 0,783 yang berarti lebih besar dari $0,60(0,783>0,60)$.

\section{Regresi Linear Sederhana dan Pengujian Hipotesis}

Berdasarkan dari tabel Model Summary pada bagian ini menjelaskan besarnya nilai persentase sumbangan pengaruh variabel independen terhadap variabel dependen sebesar 0,603 yang disebut dengan koefisien determinasi dan merupakanhasil dari penguadratan $R$. yang mengandung pengertian bahwa pengaruh kompetensi pegawai terhadap penerapan electronic government adalah sebesar $60,3 \%$.

Hasil uji ANOVA pada bagian ini ditampilkan hasil yang diperoleh adalah nilai $\mathrm{F}=47,349$ dengan tingkat probabilitas sig 0.000 . Oleh karena probabilitas $(0.000)$ jauh lebih kecil dari 0,05, maka model regresi bisa dipakai untuk memprediksi Kompetensi Pegawai. Untuk menguji kebenaran hipotesis dalam penelitian ini dilakukan uji $F$. Untuk mengetahui bahwa pengaruh/Signifikan dapat diketahui dengan melihat lefel of signifikan $a=0,05$. Jika nilai signifikan lebih kecil dari 0,05, maka $\mathrm{HO}$ ditolak dan $\mathrm{Ha}$ diterima. Berdasarkan hasil olah pada tabel ANOVA, maka diketahui nilai Fhitung yang diperoleh sebesar 47,349 dengan tingkat signifikan $0,000 \quad($ sig<0,05) yang berarti bahwa variabel Kompetensi Pegawai (X) mempunyai pengaruh/signifikan terhadap penerapan Electronic Government $(\mathrm{Y})$, dari hasil tersebut berarti model regresi dapat digunakan untuk memprediksi penerapan electronic government di Desa Timoreng Panua Kecamatan Panca Rijang Kabupaten Sidenreng Rappang.

Berdasarkan tabel Coefficients hasil olah data, maka model regresi yang digunakan dalam penelitian ini untuk mengukur pengaruh kompetensi pegawai terhadap penerapan electronic government di Desa Timoreng Panua Kecamatan Panca Rijang Kabupaten Sidenreng Rappang.

$$
Y=4,059+0,628 X
$$

Dari fungsi di atas, maka dapat dijelaskan :

1. Jika variabel Kompetensi Pegawai (X) berubah, maka penerapan Electronic Government ( $Y$ ) juga akan berubah. Tanda positif menunjukkan perubahan yang searah. Apabila Kompetensi Pegawai meningkat maka, penerapan Electronic Government juga akan meningkat dengan koefisien regresi sebesar 0,628 dan sebaliknya jika Kompetensi Pegawai juga menurun, maka penerapan Electronic Government juga akan menurun dengan koefisien regresi sebesar 0,628.

2. Nilai konstanta sebesar 4,059 menunjukkan bahwa, jika semua variabel konstan maka Kompetensi Pegawai masih bersifat positif.

Tabel Coefficients diperoleh thitung= 6,881 prosedur mencari statistic tabel dengan criteria

1. Tingkat signifikan $(a=0,05)$

2. $D f=j u m l a h$ responden -2 atau $85-2=83$

3. $\mathrm{t}$ tabel $=\mathrm{a} / 2$; $\mathrm{df}$

$$
\begin{aligned}
& =0,05 / 2 ; d f \\
& =0,025 ; 83
\end{aligned}
$$

Sehingga $\mathrm{t}$ tabel $=1,992$

Keputusan:

Ternyata nilai $\mathrm{t}$ hitung $>\mathrm{t}$ tabel atau $6,881>1,992$, maka $\mathrm{HO}$ ditolak dan $\mathrm{Ha}$ diterima, artinya signifikan. Jadi Kompetensi Pegawai berpengaruh signifikan terhadap Penerapan Electronic Government di Desa Timoreng Panua Kecamatan Panca Rijang Kabupaten Sidenreng Rappang.

Berdasarkan pada keputusan yang telah dipaparkan tentang pengujian hipotesis dapat dijelaskan bahwa $\mathrm{HO}$ ditolak dan $\mathrm{Ha}$ 
diterima dengan kata lain thitung $>$ ttabel $(6,881>1,992)$ artinya Signifikan. Dari data tersebut dapat dikatakan bahwa Kompetensi Pegawai berpengaruh signifikan terhadap Penerapan Electronic Government di Desa Timoreng Panua Kecamatan Panca Rijang Kabupaten Sidenreng Rappang. Berdasarkan data distribusi frekuensi variabel kompetensi pegawai dapat dilihat bahwa tingkat capaian responden sebesar 58,3\%. Ini memperlihatkan bahwa nilai tingkat capaian responden berada pada kategori cukup baik maka dari itu kompetensi pegawai harus tetap ditingkatkan. Sedangkan data distribusi frekuensi variabel electronic government dapat dilihat bahwa tingkat capaian responden yang diberikan adalah $56,9 \%$ yang terdiri dari 4 indikator electronic government yang dikemukakan oleh $\mathrm{R}$ Eko Indrajit yakni efisiensi, efektivitas, transparansi, dan akuntabilitas. Berdasarkan hasil analisis data tersebut diperoleh capaian responden sebesar $56,9 \%$ berada pada kategori cukup baik hal tersebut menunjukkan bahwa penerapan electronic government yang ada di Desa Timoreng Panua masih perlu ditingkatkan.

\section{KESIMPULAN}

Berdasarkan apa yang telah dipaparkan diatas, maka hal ini dapat disimpulkan bahwa;

1. Kompetensi pegawai (X) di Desa Timoreng Panua Kecamatan Panca Rijang Kabupaten Sidenreng Rappang, meliputi: pengetahuan, keahlian, kemampuan, dan sikap. Berdasarkan hasil penelitian dengan analisis distribusi frekuensi pada variabel $X$ (kompetensi pegawai) maka diperoleh rata-rata persentase sebesar $58,3 \%$ yang termasuk kategori cukup baik.

2. Electronic Government (Y) di Desa Timoreng Panua Kecamatan Panca Rijang Kabupaten Sidenreng Rappang, meliputi: efisiensi, efektivitas, transparansi, akuntabilitas. Berdasarkan hasil penelitian dengan analisis distribusi frekuensi pada variabel $Y$ (electronic government) maka diperoleh rata-rata persentase sebesar $56,9 \%$ yang termasuk kategori cukup baik.

3. Berdasarkan hasil perhitungan SPSS versi 16 maka dapat diketahui kompetensi pegawai berpengaruh terhadap penerapan electronic government, hal ini dibuktikan melalui dari tabel summary $\mathrm{R}^{2}$ sebesar 0,603 atau $60,3 \%$ dengan kategori cukup berpengaruh. Nilai thitung $=6,881>t$ tabel 1,992, maka $\mathrm{HO}$ ditolak dan $\mathrm{Ha}$ diterima artinya, signifikan. Jadi Kompetensi Pegawai berpengaruh signifikan terhadap Penerapan Electronic Government di Desa Timoreng Panua Kecamatan Panca Rijang Kabupaten Sidenreng Rappang.

\section{E. REFRENSI}

Ahmad, J. (2015). Metode Penelitian Administrasi Publik Teori dan Aplikasi. Yogyakarta: Gava Media.

Asnan Mardianto, Wahjoe Pangestoeti D.P.S. (2015). Analisis Kompetensi Pegawai (Studi Pada Tugas Pokok dan Fungsi di Kantor Satuan Polisi Pamong Praja Provinsi Kepulauan Riau).

Azkiya, H. (2008). Penerapan E-Government Dalam Peningkatan Pelayanan Publik(Studi pada Pelaksanaan Program e-Tax Pajak Restoran di Kota Malang).

Keterampilan Terhadap Kinerja Auditor Kota Metro.

Hayati dan Eko Priyo Purnomo. (2017). Implementasi E-Government pada Pemerintah Daerah Kabupaten Bantul Yogyakarta. (December).

Irvan Purnama. (2011). Implementasi Transparansidan Akuntabilitas dalam Upaya Peningkatan Kualitas Laporan Keuangan Pemerintah Daerah. Universitas Komputer Indonesia.

Julita. (2014). Analisis Efektivitas dan Efisiensi Anggaran Pendapatan dan Belanja Pada Badan Lingkungan Hidup Provinsi Sumatera Utara. Journal of Chemical Information and Modeling.

Rahmi, M. (2013). Pengaruh Penggunaan Teknologi Informasi danKeahlian Pemakai terhadap Kualitas Informasi Akuntansi.

Sakti, I. (2013). Korelasi Pengetahuan Alat Pratikum Fisika dengan Kemampuan Psikomotorik Siswa di Sina Negeri Kota Bengkulu. Exacta. 
Suhartini, E. (2014). Pengaruh Kompetensi terhadap Kinerja Pegawai (Studi Perbandingan antara Fakultas Ekonomi dan Bisnis Islam dan Fakultas Syariah dan Hukum Uinam). Jurnal UIN Alauddin Fakultas Ekonomi dan Bisnis Islam.

Zainuddin.(2017).Teori-teori Mutakhir dalam Perspektif Ilmu Administrasi Publik. Makassar: Phinatama Media.

\section{Dokumen-dokumen:}

Peraturan Presiden Republik Indonesia Nomor 95 tahun 2018 tentang Sistem Pemerintahan Berbasis Elektronik Pasal 1 ayat 3 Manajemen SPBE. 